\title{
In vivo glucose metabolism and glutamate levels in mGluR5 knockout mice: a multimodal neuroimaging study using $\left[{ }^{18} \mathrm{~F}\right] \mathrm{FDG}$ microPET and MRS
}

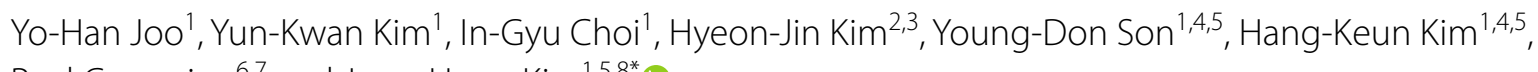
Paul Cumming ${ }^{6,7}$ and Jong-Hoon Kim ${ }^{1,5,8^{*}}$ (i)

\begin{abstract}
Background: Perturbed functional coupling between the metabotropic glutamate receptor-5 (mGluR5) and $\mathrm{N}$-methyl-D-aspartate (NMDA) receptor-mediated excitatory glutamatergic neurotransmission may contribute to the pathophysiology of psychiatric disorders such as schizophrenia. We aimed to establish the functional interaction between mGluR5 and NMDA receptors in brain of mice with genetic ablation of the mGluR5.

Methods: We first measured the brain glutamate levels with magnetic resonance spectroscopy (MRS) in mGluR5 knockout (KO) and wild-type (WT) mice. Then, we assessed brain glucose metabolism with $\left[{ }^{18} \mathrm{~F}\right]$ fluorodeoxyglucose $\left(\left[{ }^{18} \mathrm{~F}\right] \mathrm{FDG}\right)$ positron emission tomography before and after the acute administration of an NMDA antagonist, MK-801 $(0.5 \mathrm{mg} / \mathrm{kg})$, in the same mGluR5 KO and WT mice.

Results: Between-group comparisons showed no significant differences in $\left[{ }^{18} \mathrm{~F}\right] \mathrm{FDG}$ standardized uptake values (SUVS) in brain of mGluR5 KO and WT mice at baseline, but widespread reductions in mGluR5 KO mice compared to WT mice after MK-801 administration $(p<0.05)$. The baseline glutamate levels did not differ significantly between the two groups. However, there were significant negative correlations between baseline prefrontal glutamate levels and regional $\left[{ }^{18} \mathrm{~F}\right]$ FDG SUVs in mGluR5 KO mice $(p<0.05)$, but no such correlations in WT mice. Fisher's Z-transformation analysis revealed significant between-group differences in these correlations $(p<0.05)$.

Conclusions: This is the first multimodal neuroimaging study in mGluR5 KO mice and the first report on the association between cerebral glucose metabolism and glutamate levels in living rodents. The results indicate that mGluR5 KO mice respond to NMDA antagonism with reduced cerebral glucose metabolism, suggesting that mGluR5 transmission normally moderates the net effects of NMDA receptor antagonism on neuronal activity. The negative correlation between glutamate levels and glucose metabolism in mGluR5 KO mice at baseline may suggest an unmasking of an inhibitory component of the glutamatergic regulation of neuronal energy metabolism.
\end{abstract}

Keywords: mGluR5, Knockout, NMDA, Glutamate, FDG, PET, MRS

\footnotetext{
*Correspondence: jhnp@chol.com; jhnp@gachon.ac.kr

${ }^{1}$ Neuroscience Research Institute, Gachon University, Incheon, Republic

of Korea

Full list of author information is available at the end of the article
}

\section{Introduction}

Glutamate is the most abundant excitatory neurotransmitter in the brain and is consequently a major driver for neuronal energy expenditure. The energy budget of brain is uniquely dependent on oxidative phosphorylation of pyruvate derived from glycolysis [1, 2]. Nonetheless, 
neuronal energy metabolism can be assessed in vivo by using positron emission tomography (PET) with the glycolysis tracer $\left[{ }^{18} \mathrm{~F}\right]$ fluorodeoxyglucose $\left(\left[{ }^{18} \mathrm{~F}\right] \mathrm{FDG}\right)$, which gives an index of the glucose metabolism that is coupled to glutamatergic neuronal activity [3, 4]. Glutamatergic signaling plays critical roles in synaptic plasticity and the regulation of cognitive, behavioral, and affective processes [5-7]. As such, dysfunction of glutamatergic neurotransmission is implicated in the pathophysiology of major psychiatric disorders such as schizophrenia and depressive disorders $[8,9]$ and is also involved in excitotoxic and neurodegenerative diseases $[10,11]$.

The glutamate receptors in brain belong to two major classes, the ionotropic ligand-gated ion channels such as $\mathrm{N}$-methyl-D-aspartate (NMDA) receptors and a diverse family of metabotropic glutamate receptors (mGluR) linked to intracellular second messenger systems. Among the latter group, the type 5 metabotropic receptor (mGluR5) is an important player in glutamatergic signaling [12-14]. Previous studies reported that mGluR5 is functionally linked to NMDA receptors via scaffold proteins of the post-synaptic density (PSD), such as Homer, Shank, and PSD-95 [15, 16]. Increasing evidence indicates that the activation of NMDA receptors is potentiated by concomitant mGluR5-mediated signaling $[16,17]$ and that stimulation of NMDA receptors reciprocally enhances mGluR5 function $[18,19]$. The synergistic action of glutamate signaling at mGluR5/ NMDA receptors $[20,21]$ is further attested by observations that genetic ablation of mGluR5 interfered with NMDA receptor-mediated long-term potentiation in the hippocampus [22, 23]. In addition, while pharmacological antagonism of mGluR5 did not provoke deficits in the prepulse inhibition (PPI) of the acoustic startle response in rodents, mGluR5 antagonism significantly potentiated the PPI disruption induced by the NMDA receptor antagonist, MK-801 [24], suggesting a mGluR5/NMDA synergism in this important behavioral endophenotype of schizophrenia. Furthermore, recent rodent studies associate dysregulation of mGluR5/NMDA signaling with a range of neurocognitive deficits, which are among the core features of schizophrenia $[25,26]$. Thus, the further investigation of mGluR5/NMDA synergism may shed new light on the underlying characteristics of glutamatergic dysfunction in psychiatric disorders such as schizophrenia.

The mGluR5 knockout (KO) mouse model enables the investigation of behavioral phenotypes associated with metabotropic glutamatergic signaling abnormalities $[20,27]$. However, there has been no direct evaluation of mGluR5/NMDA synergism based on observations of brain energy metabolism and glutamate levels in brain of mice with genetic ablation of the mGluR5. Thus, we undertook this in vivo multimodal imaging study with groups of wild-type (WT) and mGluR5 KO mice to examine the effects of mGluR5 $\mathrm{KO}$ on brain glucose metabolism measured with $\left[{ }^{18} \mathrm{~F}\right] \mathrm{FDG}$ PET and glutamate levels measured with magnetic resonance spectroscopy (MRS). To test the reciprocal interaction between mGluR5 and NMDA receptors, we measured brain glucose metabolism before and after acute administration of the NMDA antagonist MK-801 in WT and KO mice.

\section{Materials and methods \\ Animals}

Mice heterozygous for mGluR5 (B6.129-Grm5tm1Rod/J, stock \#003558) in C57BL/6J background were purchased from Jackson Laboratory (Bar Harbor, Maine). Three pairs of the first-generation mGluR5 heterozygous mice were bred to obtain 11 mGluR5 $\mathrm{KO}$ (Grm5 -/-, six F3 and five F4) and $10 \mathrm{WT}(\mathrm{Grm} 5+/+$, six F3 and four F4) mice. The genotype of each mouse was identified by polymerase chain reaction (PCR) analysis (Macrogen, South Korea). The mice had ad libitum access to food and water and were separately housed in single-sex cages with a 12-h light-dark cycle. All experiments were approved by the Institutional Animal Care and Use Committee (IACUC) of Gachon University (GU-NRI-17-001) and Seoul National University College of Medicine (SNU16-0189-S1A1) and were carried out in strict accordance with the recommendations in the Guide for the Care and Use of Laboratory Animals 8th edition, National Research Council (2011).

\section{$\left[{ }^{18} \mathrm{~F}\right] \mathrm{FDG}$ microPET}

The $\left[{ }^{18} \mathrm{~F}\right]$ FDG microPET study was performed at Gachon University College of Medicine. Prior to PET scans, each mouse was deprived of food for at least $12 \mathrm{~h}$ and then received a bolus tail vein injection of $4.2 \pm 0.6 \mathrm{MBq}\left[{ }^{18} \mathrm{~F}\right] \mathrm{FDG}$ in approximately $200 \mu \mathrm{L}$. Baseline PET scans were followed 2 weeks later by second fasting PET scans with acute administration of MK-801 $(0.5 \mathrm{mg} / \mathrm{kg})$ at $30 \mathrm{~min}$ before $\left[{ }^{18} \mathrm{~F}\right] \mathrm{FDG}$ injection. Immediately after tracer injection, mice were placed in a holding cage for $30 \mathrm{~min}$ of $\left[{ }^{18} \mathrm{~F}\right] \mathrm{FDG}$ uptake and then rapidly anesthetized with $2.5 \%$ isoflurane in $80 \%$ oxygen. Within a minute of induction, mice were placed in the aperture of the Focus 120 microPET (Concorde Microsystems, Knoxville, TN, USA) with continued inhalation anesthesia during the recording of a single emission frame lasting $30 \mathrm{~min}$. After attenuation correction, the static PET emission images were reconstructed using a threedimensional ordered subset expectation maximization (3D-OSEM) algorithm. The voxel size was $0.216 \times 0.216 \mathrm{~mm}$ and of $0.796 \mathrm{~mm}$ thickness. The whole brain PET image of each mouse was segmented 
from the original PET images by manual editing of the extracerebral voxels using the PMOD software (PMOD version 3.9, PMOD Technologies Ltd., Zurich, Switzerland). The images were then co-registered and spatially normalized to a $\left[{ }^{18} \mathrm{~F}\right] \mathrm{FDG}$ PET mouse brain template [28] using nine parameters with statistical parametric mapping 12 (SPM12, Wellcome Trust Centre for Neuroimaging, https://www.fil.ion.ucl.ac.uk/spm) as implemented in the PMOD software. For analysis of $\left[{ }^{18} \mathrm{~F}\right] \mathrm{FDG}$ PET recordings, we calculated standardized uptake values (SUVs) for the baseline scans $\left(\mathrm{SUV}_{\mathrm{pre}}\right)$ and MK-801 challenge scans $\left(\mathrm{SUV}_{\text {post }}\right)$ using the formula: $\mathrm{SUV}=$ tissue activity concentration $\times$ body weight/injected radiotracer dose. We calculated mean SUVs in the striatum, cortex, hippocampus, thalamus, cerebellum, and whole brain $[29,30]$ using regions defined by the mouse region-of-interest (ROI) template [28]. We next calculated the percent change of SUV with the administration of MK-801 in the mGluR5 KO and WT mouse groups as follows: $\Delta \mathrm{SUV}(\%)=\frac{\mathrm{SUV}_{\text {post }}-\mathrm{SUV}_{\mathrm{pre}}}{\mathrm{SUV}_{\mathrm{pre}}} \times 100$.

\section{Magnetic resonance spectroscopy}

The MRS experiment was performed at Seoul National University College of Medicine approximately two weeks before the PET experiments. For MR data acquisition, mice were anesthetized with isoflurane (1.5\% in oxygen) and placed inside the magnet in the prone position. The respiration rate and body temperature of the animals were monitored during the MR scan. All MR data were collected on a 9.4T animal MR scanner with a singlechannel surface coil for RF transmission and signal reception (Agilent Technologies, Santa Clara, CA, USA). For voxel localization, scout images were acquired along the axial, coronal, and sagittal directions using a T2-weighted fast spin echo sequence (repetition time (TR)/echo time $(\mathrm{TE})=3000 / 33 \mathrm{~ms}$, echo train length $=4$, field of view $(\mathrm{FOV})=20 \times 20 \mathrm{~mm}^{2}$, matrix size $=256 \times 256$, slice thickness $=1 \mathrm{~mm}, 15$ slices for the axial and sagittal directions and 10 slices for the coronal direction (no gap), receiver bandwidth $(\mathrm{BW})=100 \mathrm{kHz}$, and number of signal averages $(\mathrm{NSA})=2$ ). Based on the scout images, spectroscopy voxels were positioned in the prefrontal cortex $\left(1.5 \times 1.5 \times 3.0 \mathrm{~mm}^{3}\right)$ and hippocampus $(1.5 \times 2.0 \times 2.5$ $\mathrm{mm}^{3}$ ). Then, the first- and second-order auto-shimming was performed followed by manual refinement.

${ }^{1} \mathrm{H}$-MRS data were acquired with a spin echo, fullintensity acquired localized (SPECIAL) sequence [31]. To minimize voxel displacement, the carrier frequency was adjusted by $-2.3 \mathrm{ppm}$ from the water resonance. A variable pulse power and optimized relaxation delays (VAPOR) [32] module combined with outer volume suppression (OVS) modules [33] preceded the SPECIAL sequence except for the acquisition of the double inversion recovery (DIR)-based metabolitenulled spectra. Other sequence parameters were: TR/ $\mathrm{TE}=4000 / 2.84 \mathrm{~ms}$, number of data points $=2048$, spectral $\mathrm{BW}=5 \mathrm{kHz}, 32$-step phase cycling, and 2 dummy scans. A total of 12 spectra each with NSA $=64$ were consecutively acquired for each voxel. A metabolite-nulled spectrum was acquired for each voxel as a surrogate of spectral baseline [34] using a DIR-SPECIAL sequence $(\mathrm{TR} / \mathrm{TE}=4650 / 2.84 \mathrm{~ms}, \mathrm{NSA}=320$, and $1 \mathrm{st} / 2$ nd inversion time $(\mathrm{TI})=2150 / 686 \mathrm{~ms})$.

The spectral basis set for metabolites was simulated using GAMMA [35] in response to a single spin echo sequence for metabolites, according to the reported chemical shifts and J-coupling constants [36]. Data were zero-filled to 4096 points, apodized, and phase-corrected by using jMRUI [37]. The residual water signal was removed by the HLSVD filter [38]. The individual metabolites were quantified from the spectra using AMARES [39]. The metabolite-nulled spectrum was also incorporated into the spectral basis set [34]. Only the glutamate data with a Cramer-Rao lower bound (CRLB) of $\leq 30 \%$ were included in the statistical analysis.

\section{Statistical analysis}

Between-group comparisons of $\left[{ }^{18}\right.$ F]FDG PET SUVs were performed using a linear mixed model. The mouse group and brain ROIs were treated as fixed effects and brain regions were also treated as random effects, while $\mathrm{SUV}_{\text {pre}}, \mathrm{SUV}_{\text {post }}$ and $\triangle \mathrm{SUV}$ were treated as dependent variables. We additionally applied the multivariate approach using a repeated measures analysis of variance (ANOVA) of the SUV with time (pre- versus postMK-801) as a within-subjects factor and group (mGluR5 $\mathrm{KO}$ versus WT) as a between-subjects factor, to account for interaction effects of MK-801 treatment and genotype. Given the small sample size, pairwise comparisons between $\mathrm{SUV}_{\text {pre }}$ and $\mathrm{SUV}_{\text {post }}$ were also performed using the Wilcoxon rank test. Between-group comparisons of glutamate levels were performed using the MannWhitney $U$ test. Correlation analyses between baseline regional (prefrontal cortex and hippocampus) glutamate levels and $S_{U V}$ pre were performed in a multimodal PETMRS approach. To compare between-group differences of the correlation coefficients, Fisher's Z-transformation analysis was conducted. The significance level was set at $p<0.05$ for all statistical analyses. All statistical analyses were performed using R software (version 3.5.1, R Foundation for Statistical Computing, Vienna, Austria).

\section{Results}

The demographic characteristics of the mGluR5 KO and WT mice are presented in Table 1. Between-group differences of age, sex, weight, and injected $\left[{ }^{18} \mathrm{~F}\right] \mathrm{FDG}$ dose 
Table 1 Demographic characteristics and scan parameters

\begin{tabular}{|c|c|c|c|c|}
\hline \multirow[t]{2}{*}{ Variables } & \multicolumn{2}{|l|}{ Mouse type } & \multirow[t]{2}{*}{$t$-value } & \multirow[t]{2}{*}{$p$-value } \\
\hline & $\begin{array}{l}\text { mGluR5 KO }(n=11) \\
\text { Mean } \pm \text { SD }\end{array}$ & $\begin{array}{l}\text { WT }(n=10) \\
\text { Mean } \pm \text { SD }\end{array}$ & & \\
\hline Age (day) & $252.6 \pm 68.5$ & $222.4 \pm 45.9$ & 1.66 & 0.10 \\
\hline Male/female & $8 / 3$ & $5 / 5$ & $0.39^{\dagger}$ & 0.39 \\
\hline Weight (g) & $22.9 \pm 4.2$ & $24.0 \pm 3.5$ & -0.93 & 0.36 \\
\hline $\begin{array}{l}{\left[{ }^{18} \mathrm{~F}\right] \mathrm{FDG}} \\
\text { injected } \\
\text { dose }(\mathrm{MBq})\end{array}$ & $4.1 \pm 0.6$ & $4.3 \pm 0.6$ & -1.02 & 0.32 \\
\hline $\begin{array}{l}{\left[{ }^{18} \mathrm{~F}\right] \mathrm{FDG}} \\
\text { injected } \\
\text { dose/ } \\
\text { weight } \\
(\mathrm{MBq} / \mathrm{g})\end{array}$ & $0.18 \pm 0.37$ & $0.18 \pm 0.32$ & 0.20 & 0.84 \\
\hline
\end{tabular}

KO knockout, $W T$ wild type, $S D$ standard deviation

+ Odds ratio

were not significant (Table 1). The $\mathrm{SUV}_{\text {pre }}$ and $\mathrm{SUV}_{\text {post }}$ are shown in Fig. 1a, and the $\triangle$ SUV is shown in Fig. $1 \mathrm{~b}$ for the six ROIs (Fig. 1).

\section{Between-group comparisons}

The linear mixed model analysis of $\triangle \mathrm{SUV}$ as the dependent variable showed a significant main effect of group $[\mathrm{F}(1,19)=6.62, p=0.019]$, and the linear mixed model analysis of $\mathrm{SUV}_{\text {post }}$ as the dependent variable also showed a significant main effect of group $[\mathrm{F}(1,19)=7.08, p=0.015]$. However, the analysis of $\mathrm{SUV}_{\text {pre }}$ as the dependent variable showed no significant main effect of group $[\mathrm{F}(1,19)=0.05, p=0.827]$. The Bonferroni post hoc analysis revealed significantly lower $\mathrm{SUV}_{\text {post }}$ and $\triangle \mathrm{SUV}$ in all ROIs in the mGluR5 $\mathrm{KO}$ mice compared to WT mice $(p<0.05)$, whereas there were no significant between-group differences in $\mathrm{SUV}_{\text {pre }}$ in any ROI $(p>0.1)$ (Fig. 1, Table 2). The repeated measures ANOVA also showed a significant MK-801 treatment $\mathrm{x}$ genotype interaction effect for all ROIs [cortex: $\mathrm{F}(1,19)=5.91, p=0.039$; hippocampus: $\mathrm{F}(1,19)=4.79, p=0.041$; thalamus: $\mathrm{F}(1,19)=4.68$, $p=0.043$; striatum: $\mathrm{F}(1,19)=4.45, p=0.048$, cerebellum: $\mathrm{F}(1,19)=4.42, p=0.049$; whole brain: $\mathrm{F}(1$, $19)=4.90, p=0.039]$. Additional pairwise comparisons using the Wilcoxon rank test showed significantly decreased SUVs after administration of MK-801 in all ROIs in the mGluR5 KO mice $(p<0.05)$, except for the striatum $(p=0.054)$, but no significant changes of SUVs in WT mice $(p>0.1)$ (Table 3). Among the 11 mGluR5 $\mathrm{KO}$ mice, the glutamate levels were available in the prefrontal cortex of nine mice and the hippocampus of ten mice, while MRS for glutamate was successful in all WT mice in both regions. Between-group comparisons using the Mann-Whitney $U$ test showed no significant differences in glutamate levels $(p>0.1)$ (Table 4$)$.
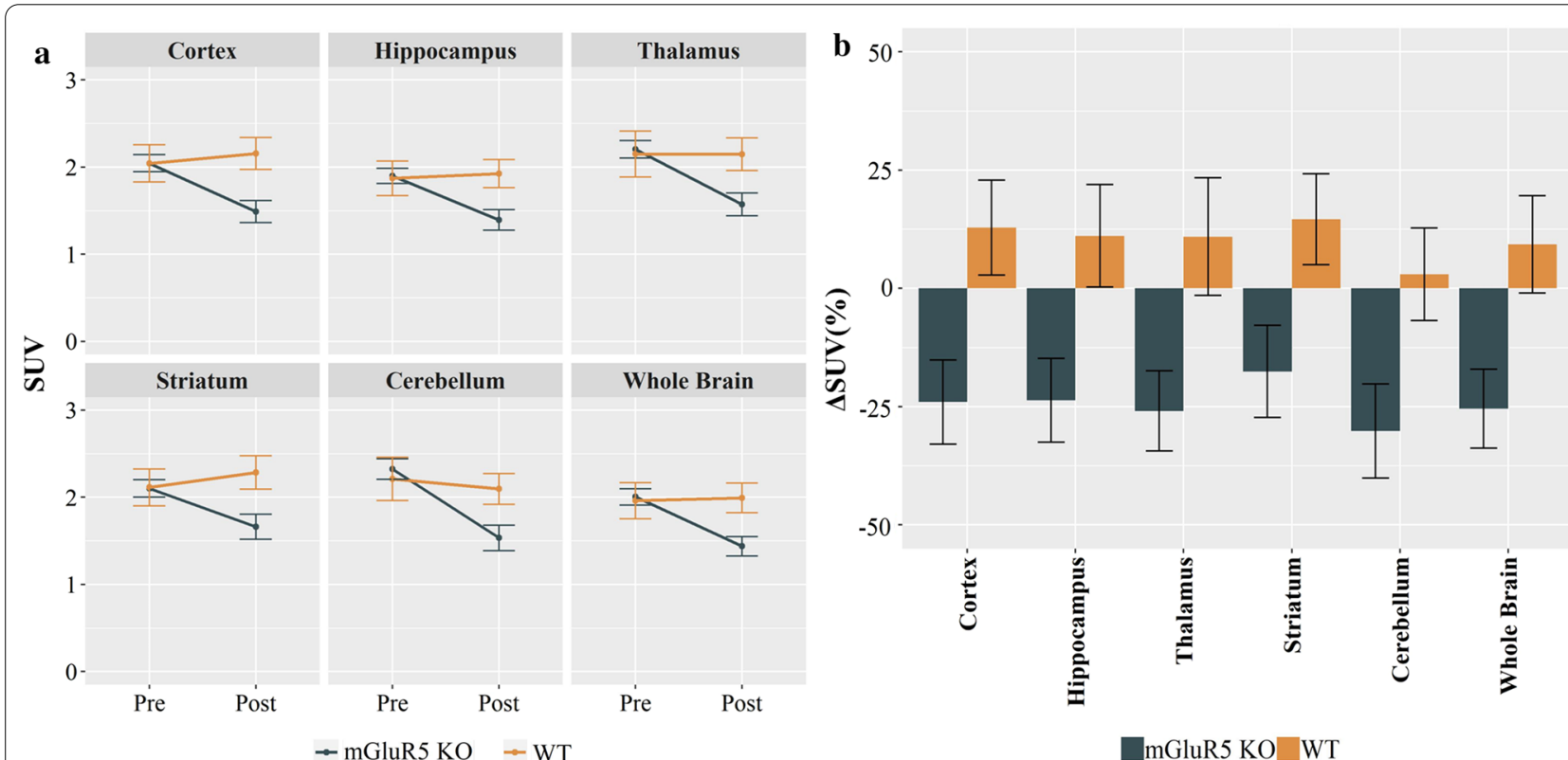

-50 -

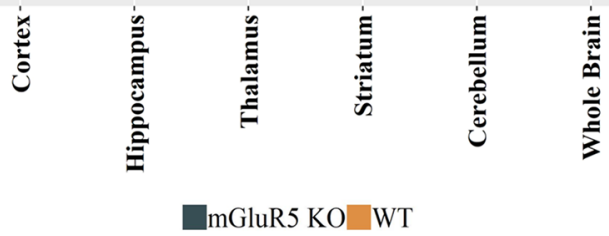

Fig. 1 The mean $\left[{ }^{18} \mathrm{~F}\right]$ FDG PET SUV and $\triangle$ SUV with standard error bars in mGluR5 KO and WT mice. a Significantly decreased SUVs were observed in mGluR5 KO mice after the acute administration of MK-801 $(p<0.05)$, whereas no significant alterations were observed in WT mice $(p>0.05)$. $\mathbf{b}$ The $\triangle S U V$ values were significantly different between mGluR5 KO and WT mice in ROIs $(p<0.05)$. SUV, standardized uptake value; $\triangle S U V$, the percent change of SUV; ROI, region of interest 
Table 2 Between-group comparisons of $\left[{ }^{18}\right.$ F]FDG PET SUV ${ }_{\text {pre' }}$ SUV ${ }_{\text {post }}$ and $\Delta S U V$ with acute MK-801 challenge

\begin{tabular}{|c|c|c|c|c|c|c|c|c|c|c|}
\hline Region & Group & $\begin{array}{l}\text { SUV }_{\text {pre }} \\
\text { Mean } \pm S D\end{array}$ & $t$ & $p$-value & $\begin{array}{l}\text { SUV }_{\text {post }} \\
\text { Mean } \pm \text { SD }\end{array}$ & $t$ & $p$-value & $\Delta$ SUV (\%) Mean \pm SD & $t$ & $p$-value \\
\hline \multirow[t]{2}{*}{ CTX } & mGluR5 KO & $2.04 \pm 0.33$ & 0.00 & 0.998 & $1.49 \pm 0.42$ & -3.00 & $0.007^{* *}$ & $-24.0 \pm 29.5$ & -2.64 & $0.016^{*}$ \\
\hline & WT & $2.04 \pm 0.68$ & & & $2.16 \pm 0.58$ & & & $12.8 \pm 31.8$ & & \\
\hline \multirow[t]{2}{*}{ HIP } & mGluR5 KO & $1.90 \pm 0.29$ & 0.11 & 0.912 & $1.39 \pm 0.40$ & -2.40 & $0.027^{*}$ & $-23.6 \pm 29.4$ & -2.49 & $0.022^{*}$ \\
\hline & WT & $1.87 \pm 0.63$ & & & $1.93 \pm 0.51$ & & & $11.1 \pm 34.2$ & & \\
\hline \multirow[t]{2}{*}{ THA } & mGluR5 KO & $2.20 \pm 0.34$ & 0.22 & 0.825 & $1.57 \pm 0.43$ & -2.60 & $0.018^{*}$ & $-25.9 \pm 28.1$ & -2.64 & $0.016^{*}$ \\
\hline & WT & $2.15 \pm 0.83$ & & & $2.15 \pm 0.60$ & & & $11.0 \pm 39.4$ & & \\
\hline \multirow[t]{2}{*}{ STR } & mGluR5 KO & $2.10 \pm 0.33$ & -0.05 & 0.961 & $1.66 \pm 0.47$ & -2.81 & $0.011^{*}$ & $-17.5 \pm 32.4$ & -2.30 & $0.033^{*}$ \\
\hline & WT & $2.11 \pm 0.67$ & & & $2.29 \pm 0.61$ & & & $14.7 \pm 30.4$ & & \\
\hline \multirow[t]{2}{*}{$C B$} & mGluR5 KO & $2.32 \pm 0.39$ & 0.47 & 0.643 & $1.53 \pm 0.49$ & -2.54 & $0.020^{*}$ & $-30.1 \pm 33.0$ & -2.37 & $0.028^{*}$ \\
\hline & WT & $2.21 \pm 0.79$ & & & $2.10 \pm 0.56$ & & & $3.0 \pm 30.9$ & & \\
\hline \multirow[t]{2}{*}{ WB } & mGluR5 KO & $2.00 \pm 0.31$ & 0.20 & 0.845 & $1.44 \pm 0.37$ & -2.79 & $0.011^{*}$ & $-25.4 \pm 27.6$ & -2.65 & $0.016^{*}$ \\
\hline & WT & $1.96 \pm 0.66$ & & & $1.99 \pm 0.53$ & & & $9.3 \pm 32.4$ & & \\
\hline
\end{tabular}

SUV standardized brain uptake value for $\left[{ }^{18} \mathrm{~F}\right] \mathrm{FDG}, \triangle S U V$ the percent change of SUV, SD standard deviation, KO knockout, WT wild type, CTX cortex, HIP hippocampus, THA thalamus, STR striatum, $C B$ cerebellum, WB whole brain

${ }^{*} p<0.05,{ }^{* *} p<0.01$

\begin{tabular}{|c|c|c|c|c|c|}
\hline Group & Region & $\begin{array}{l}\text { SUV }_{\text {pre }} \\
\text { Mean } \pm S D\end{array}$ & $\begin{array}{l}\text { SUV }_{\text {post }} \\
\text { Mean } \pm S D\end{array}$ & $w$ & $p$ value \\
\hline \multirow[t]{6}{*}{ mGluR5 KO } & CTX & $2.04 \pm 0.33$ & $1.49 \pm 0.42$ & 8 & $0.024^{*}$ \\
\hline & HIP & $1.90 \pm 0.29$ & $1.39 \pm 0.40$ & 8 & $0.024^{*}$ \\
\hline & THA & $2.20 \pm 0.34$ & $1.57 \pm 0.43$ & 6 & $0.014^{*}$ \\
\hline & STR & $2.10 \pm 0.33$ & $1.66 \pm 0.47$ & 11 & 0.054 \\
\hline & $C B$ & $2.32 \pm 0.39$ & $1.53 \pm 0.49$ & 5 & $0.010^{* *}$ \\
\hline & WB & $2.00 \pm 0.31$ & $1.44 \pm 0.37$ & 6 & $0.014^{*}$ \\
\hline \multirow[t]{6}{*}{ WT } & CTX & $2.04 \pm 0.68$ & $2.16 \pm 0.58$ & 38 & 0.322 \\
\hline & HIP & $1.87 \pm 0.63$ & $1.93 \pm 0.51$ & 37 & 0.375 \\
\hline & THA & $2.15 \pm 0.83$ & $2.15 \pm 0.60$ & 30 & 0.846 \\
\hline & STR & $2.11 \pm 0.67$ & $2.29 \pm 0.61$ & 41 & 0.193 \\
\hline & $C B$ & $2.21 \pm 0.79$ & $2.10 \pm 0.56$ & 29 & 0.922 \\
\hline & WB & $1.96 \pm 0.66$ & $1.99 \pm 0.53$ & 34 & 0.557 \\
\hline
\end{tabular}

KO knockout, $W T$ wild type, SUV standardized uptake value, $S D$ standard deviation, CTX cortex, HIP hippocampus, THA thalamus, STR striatum, CB cerebellum, $W B$ whole brain

${ }^{*} p<0.05,{ }^{* *} p<0.01$

\section{Correlation analyses}

The correlation analysis showed significant negative correlations between baseline glutamate levels in the prefrontal cortex and $\mathrm{SUV}_{\text {pre }}$ in the six ROIs in mGluR5 KO mice: cortex $(\mathrm{rho}=-0.83, p=0.005)$, striatum (rho $=-0.90, p=0.001$ ), hippocampus (rho $=-0.75$, $p=0.020$ ), thalamus (rho $=-0.68, p=0.042)$, cerebellum (rho $=-0.73, p=0.025)$, and whole brain (rho $=-0.82$, $p=0.007$ ) (Table 5, Fig. 2). However, there were no significant correlations between prefrontal glutamate levels and $\mathrm{SUV}_{\text {pre }}$ in WT mice $(p>0.1)$ (Table 5, Fig. 2). The Fisher's Z-transformation analysis revealed significant between-group differences of correlation coefficients between glutamate levels in the prefrontal cortex and $\mathrm{SUV}_{\text {pre }}$ in the three ROIs as follows: cortex $(z=-2.30$, $p=0.022)$, striatum $(z=-2.77, p=0.006)$, and whole brain $(z=-2.01, p=0.045)$ (Table 5, Fig. 2). There were no significant correlations between baseline hippocampal glutamate levels and $\mathrm{SUV}_{\text {pre }}$ in either mGluR5 KO or WT mice $(p>0.1)$ (Table 5).

Table 4 Between-group comparisons of glutamate levels measured using magnetic resonance spectroscopy

\begin{tabular}{lllllll}
\hline & Region & Group & Mean \pm SD & $\boldsymbol{w}$ & $\boldsymbol{p}$ value & Effect size \\
\hline Glutamate & HIP & mGluR5 KO & $0.70 \pm 0.11$ & 58 & 0.579 & 0.135 \\
& WT & mGluR5 KO & $1.02 \pm 0.17$ & 37 & 0.549 & 0.150 \\
& PT & WT & $1.14 \pm 0.42$ & & & \\
\hline
\end{tabular}


Table 5 Correlation coefficients between cortical glutamate levels and baseline $\left[{ }^{18} \mathrm{~F}\right] \mathrm{FDG}$ PET results (SUV pre) with Fisher's Z-transformation

\begin{tabular}{|c|c|c|c|c|c|c|c|c|c|}
\hline \multirow[t]{2}{*}{ MRS region } & \multirow[t]{2}{*}{ PET region } & \multicolumn{3}{|c|}{ mGluR5 KO } & \multicolumn{3}{|l|}{ WT } & \multirow[t]{2}{*}{ Fisher's Z } & \multirow[t]{2}{*}{$p$ value } \\
\hline & & $n$ & Rho & $p$ value & $n$ & Rho & $p$ value & & \\
\hline \multirow[t]{6}{*}{ PFC } & CTX & 9 & -0.83 & $0.005^{* *}$ & 10 & 0.08 & 0.829 & -2.30 & $0.022^{*}$ \\
\hline & HIP & 9 & -0.75 & $0.020^{*}$ & 10 & 0.02 & 0.960 & -1.78 & 0.075 \\
\hline & THA & 9 & -0.68 & $0.042^{*}$ & 10 & -0.03 & 0.934 & -1.45 & 0.148 \\
\hline & STR & 9 & -0.90 & $0.001^{* * *}$ & 10 & 0.07 & 0.855 & -2.77 & $0.006^{* *}$ \\
\hline & $C B$ & 9 & -0.73 & $0.025^{*}$ & 10 & 0.05 & 0.881 & -1.78 & 0.075 \\
\hline & WB & 9 & -0.82 & $0.007^{* *}$ & 10 & -0.03 & 0.934 & -2.01 & $0.045^{*}$ \\
\hline \multirow[t]{6}{*}{ HIP } & CTX & 10 & 0.09 & 0.803 & 10 & 0.09 & 0.803 & 0.00 & 1.000 \\
\hline & HIP & 10 & 0.19 & 0.603 & 10 & 0.18 & 0.627 & 0.02 & 0.982 \\
\hline & THA & 10 & 0.05 & 0.881 & 10 & 0.24 & 0.511 & -0.35 & 0.729 \\
\hline & STR & 10 & 0.27 & 0.446 & 10 & 0.04 & 0.907 & 0.45 & 0.656 \\
\hline & $C B$ & 10 & 0.13 & 0.726 & 10 & 0.15 & 0.676 & -0.05 & 0.962 \\
\hline & WB & 10 & 0.03 & 0.934 & 10 & 0.24 & 0.511 & -0.51 & 0.613 \\
\hline
\end{tabular}

SUV standardized uptake value, KO knockout, WT wild type, PFC prefrontal cortex, CTX cortex, HIP hippocampus, THA thalamus, STR striatum, CB cerebellum, WB whole brain

${ }^{*} p<0.05,{ }^{* *} p<0.01,{ }^{* * *} p<0.001$

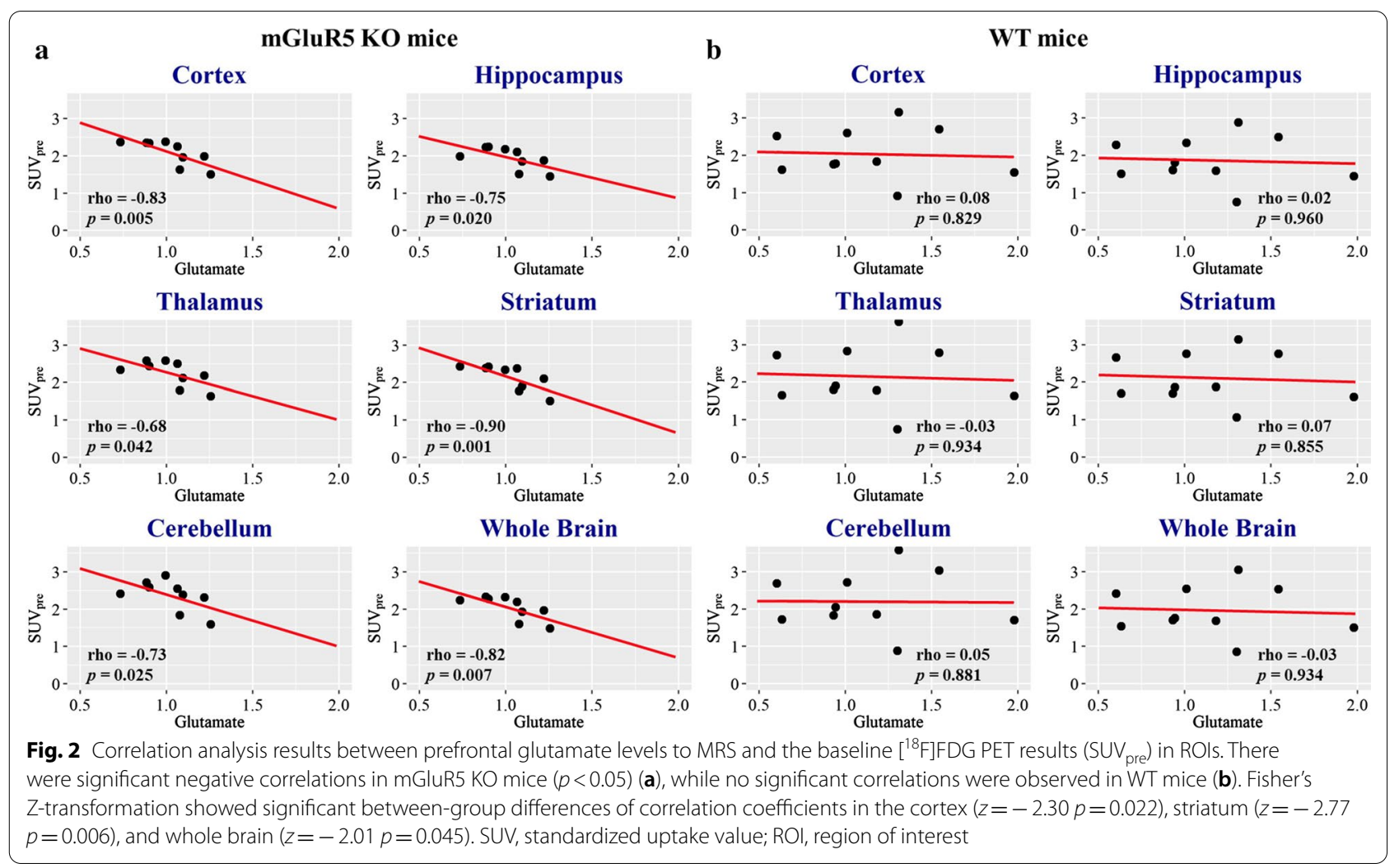

\section{Discussion}

We examined the effects of mGluR5 genetic deletion on cerebral glucose metabolism measured with $\left[{ }^{18} \mathrm{~F}\right]$ FDG PET and glutamate levels measured using MRS in living mice. While glutamate levels were measured only at baseline, we measured $\left[{ }^{18} \mathrm{~F}\right] \mathrm{FDG}$ PET uptake before and after acute administration of the potent NMDA antagonist MK-801, aiming to probe the interaction 
between mGluR5 and NMDA receptors by regarding cerebral glucose metabolism as a proxy for net neuronal activity. At baseline, there were no significant group differences in brain glucose metabolism between mGluR5 $\mathrm{KO}$ and WT mice. However, we observed significantly lower glucose metabolism in the MK-801 challenge condition relative to baseline in the mGluR5 KO mice. There were significant negative correlations between prefrontal glutamate levels and regional glucose metabolism in mGluR5 KO mice, but no such correlations in WT mice, nor did glutamate levels differ between the mGluR5 KO and WT mice at baseline. Thus, treatment with the NMDA antagonist perturbed cerebral $\left[{ }^{18} \mathrm{~F}\right] \mathrm{FDG}$ uptake only in the mGluR5 $\mathrm{KO}$ mice. This observation of an interaction between mGluR5 genetic deletion and acute MK-801 administration resulting in net global hypometabolism seems to be in line with the reported reciprocal potentiation between glutamate signaling at mGluR 5 and NMDA receptors [20, 21].

In our study, there was no statistically significant effect of acute MK-801 treatment on cerebral $\left[{ }^{18} \mathrm{~F}\right] \mathrm{FDG}$ uptake in WT mice. A subanesthetic dose of the NMDA antagonist ketamine increased $\left[{ }^{18} \mathrm{~F}\right] \mathrm{FDG}$ uptake in some rat brain regions [40]. Similarly, previous rodent studies reported focal increases in $\left[{ }^{18} \mathrm{~F}\right] \mathrm{FDG}$ trapping in retrosplenial and posterior cingulate cortices after a single dose of MK-801 (0.4 mk/kg) [41] and decreased [ $\left.{ }^{18} \mathrm{~F}\right] \mathrm{FDG}$ uptake after one week of daily MK-801 administration $(0.3 \mathrm{mg} / \mathrm{kg})$ [42]. Our finding of a trend toward a global $10 \%$ increase in $\left[{ }^{18} \mathrm{~F}\right] \mathrm{FDG}$ uptake (Fig. 1) in the WT group was obscured by the high relative standard deviation in the baseline evaluation of SUV. However, sample size calculation for our finding of a $10 \%$ increase in SUV with a $15 \%$ relative standard deviation predicts that we would have needed much larger populations of mice to avoid a type II statistical error.

Previous microdialysis studies showed that MK-801 treatment acutely increases extraneuronal glutamate levels in rodent brain [43-45], which has been attributed to a net disinhibition of glutamate release via blockade of excitatory inputs to gamma-aminobutyric acid (GABA)-ergic interneurons in the cerebral cortex [46, 47]. The present lack of significant effect of MK-801 on cerebral $\left[{ }^{18} \mathrm{~F}\right] \mathrm{FDG}$ uptake in WT mice suggests that any stimulation of glucose consumption via increased activation by endogenous glutamate at mGluR5 and other non-NDMA sites may normally be roughly balanced by a reduced drive of neuronal activity arising from acute blockade of the NMDA sites. However, this putative balance was absent in the mGluR5 KO mice after MK-801 challenge, where we observed a global and highly significant $25 \%$ reduction in $\left[{ }^{18} \mathrm{~F}\right] \mathrm{FDG}$ uptake relative to baseline. Assuming the MK-801 treatment indeed increased glutamate release, we suppose that absent mGluR5 signaling resulted in failure to accommodate for the reduced metabolic drive from the blocked NMDA receptors. We suppose that these results have some relevance for excitotoxicity of glutamate in the context of "Olney's lesion," which refers to neurovacuolation and mitochondrial damage confined to the posterior cingulate and retrosplenial cortices of rats treated with MK-801 and other NMDA antagonists [48]. Interestingly, these are the same regions showing hypermetabolism on $\left[{ }^{18} \mathrm{~F}\right] \mathrm{FDG}$ PET in the acute MK-801 rat study by Shirakawa et al. [41] cited above. The present findings thus suggest a testable hypothesis that mGluR5 KO mice should be protected from Olney's lesion, by virtue of the attenuation of global neuronal activity seen with $\left[{ }^{18} \mathrm{~F}\right]$ FDG PET.

In the MRS arm of the study, we observed no significant differences in baseline prefrontal and hippocampal glutamate levels between the WT and mGluR5 KO mice, nor did we see any relationship between individual glutamate levels and regional $\left[{ }^{18} \mathrm{~F}\right] \mathrm{FDG}$ SUVs in the WT animals. However, there were significant inverse correlations between glutamate levels in the prefrontal cortex and regional $\left[{ }^{18} \mathrm{~F}\right] \mathrm{FDG}$ uptake in the mGluR5 $\mathrm{KO}$ mice. This might imply that mGluR5 KO unmasks a coupling between brain glutamate levels in the prefrontal cortex and global neuronal activity, which is normally obscured in WT mice. We can only speculate how this might arise, but we note that AMP-activated protein kinase (AMPK) phosphorylation is suppressed in mice with genetic ablation of mGluR5 [49]. Given that AMPK is critically involved in the regulation of glycolysis and mitochondrial respiration in response to synaptic activity [50], its homeostatic regulation may be perturbed in mGluR $5 \mathrm{KO}$ mice, thus contributing to the emergence of the negative correlation between prefrontal glutamate and regional $\left[{ }^{18} \mathrm{~F}\right]$ FDG uptake. There is little precedent for this finding, as there seems to be no previous studies linking glutamate levels with $\left[{ }^{18} \mathrm{~F}\right] \mathrm{FDG}$ uptake in rodent brain. One report in Alzheimer's disease patients reported no correlation between the amplitude of the glutamate/glutamine peak and the globally normalized $\left[{ }^{18} \mathrm{~F}\right] \mathrm{FDG}$ SUV [51]. Another such multimodal study in epilepsy patients showed a significant correlation between the glutamate signal and $\left[{ }^{18} \mathrm{~F}\right]$ FDG uptake in the cortex contralateral to the epileptic focus [52]. Thus, there is a clear need for further investigation of these relationships in healthy and diseased brain.

Accumulating evidence suggests that glutamatergic signaling, particularly via NMDA receptors, is altered in schizophrenia [53]. A recent postmortem brain study demonstrated a significant attenuation of mGluR5 signaling in the prefrontal cortex from patients with schizophrenia, which was associated with reduced NMDA 
receptor phosphorylation, suggesting that disruption of reciprocal interaction between mGluR5 and NMDA signaling is integral to glutamatergic dysfunction in schizophrenia [54]. Our present results in mGluR5 KO mice revealed significantly perturbed brain glucose metabolism that emerged only upon administration of the NMDA antagonist, thus implying an interaction of the two types of glutamate receptor in regulating brain glucose metabolism. Along with previous reports that mGluR5 antagonists significantly potentiate MK-801-induced neurocognitive deficits in rats that resemble the cognitive symptoms of schizophrenia $[24,55]$, our results suggest that the mGluR5s may have little independent effects on brain glucose metabolism other than those mediated by interaction with NMDA receptors. A very recent PET study reported that lower mGluR5 availability in the left temporal cortex and caudate was associated with more severe negative symptoms and worse cognitive performance in male patients with chronic schizophrenia [56]. Given these clinical and preclinical results, it should prove important to assess the relationships between mGluR5 availability, glutamate levels, and $\left[{ }^{18} \mathrm{~F}\right]$ FDG uptake in patients with schizophrenia.

We acknowledge some limitations of the present study. The relatively small sample size may have limited the statistical power to detect group differences in the baseline PET and MRS measurements. In WT mice, the relative standard deviation of the means of baseline SUVs and prefrontal glutamate levels exceeded those in mGluR5 KO mice. However, the variances are in the range of those in previous studies $[57,58]$. In the MRS arm of the study, we measured only baseline glutamate levels. An additional study arm to measure glutamate levels after acute administration of MK-801 in mGluR5 $\mathrm{KO}$ and WT mice might have confirmed our interpretation that absent mGluR5 signaling results in failure to accommodate the reduced metabolic drive from blocked NMDA receptors, in spite of MK-801-induced glutamate release. This additional study would also have clarified the possible coupling/decoupling of cortical glutamate levels and global neuronal activity in mGluR5 $\mathrm{KO}$ and WT mice. Given the reported association between dysregulation of the mGluR5/ NMDA system with the pathophysiology of schizophrenia, we measured glutamate levels only in the prefrontal cortex and hippocampus, the two cortical regions most critically implicated in the schizophrenia pathophysiology [59]. Future studies may be needed to investigate whether glutamate levels are altered in other brain areas in mGluR5 KO mice. In addition, given the global nature of glutamatergic signaling, investigations of other regions including the striatum and thalamus would be necessary to assess the broader regional correlations between glutamate levels and $\left[{ }^{18} \mathrm{~F}\right] \mathrm{FDG}$ uptake in mGluR5 $\mathrm{KO}$ and WT mice. Since we had no vehicle or placebo group to control for comparisons in our MK-801 challenge experiments, we cannot exclude the possibility of confounds such as differential responses to stress in mGluR5 KO and WT mice. Since we did not measure blood glucose levels, we cannot exclude the possibility that treatment and genotype influenced plasma glucose levels, and thus $\left[{ }^{18} \mathrm{~F}\right] \mathrm{FDG}$ uptake. However, the previous investigation of a tracer for detecting pancreatic $\beta$-cell mass did not show any effects of MK-801 treatment on glucose-stimulated insulin secretion, from which we infer that present results were not due to global effects of plasma glucose in mGluR5 KO $[60,61]$. Moreover, the largest MK801-induced SUV decrease in the KO mice was in the cerebellum $(\triangle \mathrm{SUV}:-30.1 \%)$, whereas the smallest MK801-induced SUV increase in the WT mice occurred in the cerebellum $(\triangle \mathrm{SUV}$ : $3.0 \%)$. This finding of regional differences in MK-801-induced changes in $\left[{ }^{18} \mathrm{~F}\right] \mathrm{FDG}$ uptake also argues against peripheral effects.

In conclusion, this is the first report on cerebral glucose metabolism and glutamate levels in living mGluR5 KO mice and the first report on the association between glucose metabolism and glutamate levels in living rodents. We observed no significant group differences in baseline $\left[{ }^{18} \mathrm{~F}\right]$ FDG PET measurements or MRS glutamate levels between WT and mGluR5 KO mice. However, there was a substantial decline in $\left[{ }^{18} \mathrm{~F}\right] \mathrm{FDG}$ SUVs specifically in the mGluR5 KO mice after challenge with an NMDA antagonist, suggesting that mGluR5 transmission normally moderates the net effects of NMDA receptor antagonism on glucose metabolism, i.e., neuronal activity. We also found significant inverse correlations between prefrontal glutamate levels and $\left[{ }^{18} \mathrm{~F}\right] \mathrm{FDG}$ uptake in widespread brain areas at baseline in the mGluR5 KO mice, suggesting the unmasking of an inhibitory component of the glutamatergic regulation of neuronal energy metabolism. Our study also suggests that multimodal neuroimaging in combination with pharmacological challenge using the mGluR5 KO mouse model may help to elucidate the nature of mGluR5/NMDA receptor interactions in the control of cerebral metabolism, with implications for disorders such as schizophrenia.

\section{Abbreviations}

AMPK: AMP-activated protein kinase; BW: Bandwidth; 3D-OSEM: Threedimensional ordered subset expectation maximization; $\left.\left[{ }^{18} \mathrm{~F}\right] \mathrm{FDG}:{ }^{18} \mathrm{~F}\right]$ fluorodeoxyglucose; FOV: Field of view; GABA: Gamma-aminobutyric acid; IACUC: Institutional Animal Care and Use Committee; KO: Knockout; mGluR5: Metabotropic glutamate receptor-5; MRS: Magnetic resonance spectroscopy; NMDA: $\mathrm{N}$-methyl-D-aspartate; NSA: Number of signal averages; OVS: Outer volume suppression; PCR: Polymerase chain reaction; PET: Positron emission tomography; PPI: Prepulse inhibition; SPECIAL: Spin echo, full-intensity acquired localized; SPM12: Statistical parametric mapping 12; SUV: Standardized uptake 
value; $\triangle S U V$ : The percent change of SUV; TE: Echo time; TR: Repetition time; VAPOR: Variable pulse power and optimized relaxation delays; WT:Wild type.

\section{Acknowledgements}

Not applicable.

\section{Authors' contributions}

JHK and PC contributed to the conceptualization. YHJ, YKK, IGC, HJK, YDS, HKK, $\mathrm{PC}$, and JHK contributed to the experimental designs, data acquisition, data analysis, and discussion. YKK, IGC, and JHK performed the statistical analysis. YHJ, YKK, IGC, PC, and JHK prepared the original draft and wrote the paper. All authors read and approved the final manuscript.

\section{Funding}

This research was supported by the Brain Research Program through the National Research Foundation of Korea (NRF) funded by the Ministry of Science, ICT \& Future Planning (2016M3C7A1914451).

\section{Availability of data and materials}

The datasets used and/or analyzed during the current study are available from the corresponding author on request.

\section{Ethics approval and consent to participate}

All experiments were approved by the Institutional Animal Care and Use Committee (IACUC) of Gachon University and Seoul National University College of Medicine.

\section{Consent for publication}

Not applicable.

\section{Competing interests}

The authors declare that they have no conflict of interest.

\section{Author details}

${ }^{1}$ Neuroscience Research Institute, Gachon University, Incheon, Republic of Korea. ${ }^{2}$ Department of Biomedical Sciences, Seoul National University, Seoul, Republic of Korea. ${ }^{3}$ Department of Radiology, Seoul National University Hospital, Seoul, Republic of Korea. ${ }^{4}$ Department of Biomedical Engineering, College of Health Science, Gachon University, Incheon, Republic of Korea. ${ }^{5}$ Gachon Advanced Institute for Health Science and Technology, Graduate School, Gachon University, Incheon, South Korea. ${ }^{6}$ Institute of Nuclear Medicine, Inselspital, Bern University, Bern, Switzerland. ${ }^{7}$ School of Psychology and Counselling, Queensland University of Technology, Brisbane, Australia. ${ }^{8}$ Department of Psychiatry, Research Center for Psychiatry and Behavioral Sciences, Neuroscience Research Institute, Gachon University College of Medicine, Gil Medical Center, Gachon University, 1198 Guwol-dong, Namdong-gu, Incheon 405-760, South Korea.

Received: 16 June 2020 Accepted: 24 September 2020 Published online: 02 October 2020

\section{References}

1. Pellerin L. Food for thought: the importance of glucose and other energy substrates for sustaining brain function under varying levels of activity. Diabetes Metab. 2010;36:S59-63.

2. Karaca M, Frigerio F, Migrenne S, Martin-Levilain J, Skytt DM, Pajecka K, et al. GDH-dependent glutamate oxidation in the brain dictates peripheral energy substrate distribution. Cell Rep. 2015;13:365-75.

3. Pellerin L, Magistretti PJ. Glutamate uptake into astrocytes stimulates aerobic glycolysis: a mechanism coupling neuronal activity to glucose utilization. PNAS. 1994;91:10625-9.

4. Zimmer ER, Parent MJ, Souza DG, Leuzy A, Lecrux C, Kim H-I, et al. [18F] FDG PET signal is driven by astroglial glutamate transport. Nat Neurosci. 2017;20:393-5.

5. Cain DP. LTP, NMDA, genes and learning. Curr Opin Neurobiol. 1997;7:235-42.
6. Barkus C, McHugh SB, Sprengel R, Seeburg PH, Rawlins JNP, Bannerman DM. Hippocampal NMDA receptors and anxiety: at the interface between cognition and emotion. Eur J Pharmacol. 2010;626:49-56.

7. Duman RS, Voleti B. Signaling pathways underlying the pathophysiology and treatment of depression: novel mechanisms for rapid-acting agents. Trends Neurosci. 2012;35:47-56.

8. Steele D, Moore RL, Swan NA, Grant JS, Keltner NL. Biological perspectives: the role of glutamate in schizophrenia and its treatment. Perspect Psychiatric Care. 2012;48:125-8.

9. Deutschenbaur L, Beck J, Kiyhankhadiv A, Mühlhauser M, Borgwardt S, Walter M, et al. Role of calcium, glutamate and NMDA in major depression and therapeutic application. Prog Neuropsychopharmacol Biol Psychiatry. 2016;64:325-33.

10. Olloquequi J, Cornejo-Córdova E, Verdaguer E, Soriano FX, Binvignat $\mathrm{O}$, Auladell C, et al. Excitotoxicity in the pathogenesis of neurological and psychiatric disorders: therapeutic implications. J Psychopharmacol. 2018;32:265-75.

11. Willard SS, Koochekpour S. Glutamate, glutamate receptors, and downstream signaling pathways. Int J Biol Sci. 2013;9:948-59.

12. Newell KA, Matosin N. Rethinking metabotropic glutamate receptor 5 pathological findings in psychiatric disorders: implications for the future of novel therapeutics. BMC Psychiatry. 2014;14:23.

13. Chana G, Laskaris L, Pantelis C, Gillett P, Testa R, Zantomio D, et al. Decreased expression of mGluR5 within the dorsolateral prefrontal cortex in autism and increased microglial number in mGluR5 knockout mice: Pathophysiological and neurobehavioral implications. Brain Behav Immun. 2015;49:197-205.

14. Shin S, Kwon O, Kang Jl, Kwon S, Oh S, Choi J, et al. mGluR5 in the nucleus accumbens is critical for promoting resilience to chronic stress. Nat Neurosci. 2015;18:1017-24.

15. Tu JC, Xiao B, Naisbitt S, Yuan JP, Petralia RS, Brakeman P, et al. Coupling of mGluR/homer and PSD-95 complexes by the shank family of postsynaptic density proteins. Neuron. 1999;23:583-92.

16. Chen $\mathrm{H}-\mathrm{H}$, Liao P-F, Chan M-H. mGluR5 positive modulators both potentiate activation and restore inhibition in NMDA receptors by PKC dependent pathway. J Biomed Sci. 2011;18:19.

17. Lea PM, Custer SJ, Vicini S, Faden Al. Neuronal and glial mGluR5 modulation prevents stretch-induced enhancement of NMDA receptor current. Pharmacol Biochem Behav. 2002;73:287-98.

18. Alagarsamy S, Sorensen SD, Conn PJ. Coordinate regulation of metabotropic glutamate receptors. Curr Opin Neurobiol. 2001;11:357-62.

19. Alagarsamy S, Saugstad J, Warren L, Mansuy IM, Gereau RW, Conn PJ. NMDA-induced potentiation of mGluR5 is mediated by activation of protein phosphatase 2B/calcineurin. Neuropharmacology. 2005;49:135-45.

20. Chen $\mathrm{H}-\mathrm{H}$, Stoker A, Markou A. The glutamatergic compounds sarcosine and $\mathrm{N}$-acetylcysteine ameliorate prepulse inhibition deficits in metabotropic glutamate 5 receptor knockout mice. Psychopharmacology. 2010;209:343-50.

21. Gregory KJ, Dong EN, Meiler J, Conn PJ. Allosteric modulation of metabotropic glutamate receptors: structural insights and therapeutic potential. Neuropharmacology. 2011;60:66-81.

22. Jia Z, Lu Y, Henderson J, Taverna F, Romano C, Abramow-Newerly W, et al. Selective abolition of the NMDA component of long-term potentiation in mice lacking mGluR5. Learn Mem. 1998;5:331-43.

23. Lu Y-M, Jia Z, Janus C, Henderson JT, Gerlai R, Wojtowicz JM, et al. Mice lacking metabotropic glutamate receptor 5 show impaired learning and reduced CA1 long-term potentiation (LTP) but normal CA3 LTP. J Neurosci. 1997;17:5196-205.

24. Pietraszek M, Gravius A, Schäfer D, Weil T, Trifanova D, Danysz W. mGluR5, but not mGluR1, antagonist modifies MK-801-induced locomotor activity and deficit of prepulse inhibition. Neuropharmacology. 2005;49:73-85.

25. Barnes SA, Pinto-Duarte A, Kappe A, Zembrzycki A, Metzler A, Mukamel EA, et al. Disruption of mGluR5 in parvalbumin-positive interneurons induces core features of neurodevelopmental disorders. Mol Psychiatry. 2015;20:1161-72.

26. Bhardwaj SK, Ryan RT, Wong TP, Srivastava LK. Loss of dysbindin-1, a risk gene for schizophrenia, leads to impaired group 1 metabotropic glutamate receptor function in mice. Front Behav Neurosci. 2015;9:72.

27. Gray L, van den Buuse M, Scarr E, Dean B, Hannan AJ. Clozapine reverses schizophrenia-related behaviours in the metabotropic glutamate 
receptor 5 knockout mouse: association with $\mathrm{N}$-methyl-d-aspartic acid receptor up-regulation. Int J Neuropsychopharmacol. 2009;12:45-60.

28. Mirrione MM, Schiffer WK, Fowler JS, Alexoff DL, Dewey SL, Tsirka SE. A novel approach for imaging brain-behavior relationships in mice reveals unexpected metabolic patterns during seizures in the absence of tissue plasminogen activator. Neurolmage. 2007;38:34-42.

29. Patel S, Hamill TG, Connolly B, Jagoda E, Li W, Gibson RE. Species differences in mGluR5 binding sites in mammalian central nervous system determined using in vitro binding with [18F]F-PEB. Nucl Med Biol. 2007;34:1009-17.

30. Fang XT, Eriksson J, Antoni G, Yngve U, Cato L, Lannfelt L, et al. Brain mGluR5 in mice with amyloid beta pathology studied with in vivo [11C] ABP688 PET imaging and ex vivo immunoblotting. Neuropharmacology. 2017;113:293-300,

31. Mlynárik V, Gambarota G, Frenkel H, Gruetter R. Localized short-echotime proton MR spectroscopy with full signal-intensity acquisition. Magn Reson Med. 2006;56:965-70.

32. Tkáč I, Starčuk Z, Choi I-Y, Gruetter R. In vivo 1H NMR spectroscopy of rat brain at 1 ms echo time. Magn Reson Med. 1999;41:649-56.

33. Tkáć I, Gruetter R. Methodology of1 H NMR spectroscopy of the human brain at very high magnetic fields. Appl Magn Reson. 2005;29:139.

34. Cudalbu C, MlynárikV, Gruetter R. Handling macromolecule signals in the quantification of the neurochemical profile. J Alzheimer's Dis. 2012:31:S101-15.

35. Smith SA, Levante TO, Meier BH, Ernst RR. Computer simulations in magnetic resonance. An object-oriented programming approach. J Magn Reson Ser A. 1994:106:75-105.

36. Govindaraju V, Young K, Maudsley AA. Proton NMR chemical shifts and coupling constants for brain metabolites. NMR Biomed. 2000;13:129-53.

37. Naressi A, Couturier C, Devos JM, Janssen M, Mangeat C, de Beer R, et al. Java-based graphical user interface for the MRUI quantitation package. MAGMA. 2001;12:141.

38. Cabanes E, Confort-Gouny S, Le Fur Y, Simond G, Cozzone PJ. Optimization of residual water signal removal by HLSVD on simulated short echo time proton MR spectra of the human brain. J Magn Reson. 2001;150:116-25.

39. Vanhamme L, van den Boogaart A, Van Huffel S. Improved method for accurate and efficient quantification of MRS data with use of prior knowledge. J Magn Reson. 1997;129:35-43.

40. Radford KD, Park TY, Jaiswal S, Pan H, Knutsen A, Zhang M, et al. Enhanced fear memories and brain glucose metabolism (18 F-FDG-PET) following sub-anesthetic intravenous ketamine infusion in Sprague-Dawley rats. Transl Psychiatry. 2018;8:1-12.

41. Shirakawa T, Mitsuoka K, Kuroda K, Miyoshi S, Shiraki K, Naraoka H, et al. [18F]FDG-PET as an imaging biomarker to NMDA receptor antagonistinduced neurotoxicity. Toxicol Sci. 2013;133:13-21.

42. Kosten $L$, Verhaeghe J, Verkerk R, Thomae D, De Picker L, wyffels $L$, et al. Multiprobe molecular imaging of an NMDA receptor hypofunction rat model for glutamatergic dysfunction. Psychiatry Res Neuroimaging. 2016;248:1-11.

43. Tsukada H, Nishiyama S, Fukumoto D, Sato K, Kakiuchi T, Domino EF. Chronic NMDA antagonism impairs working memory, decreases extracellular dopamine, and increases D1 receptor binding in prefrontal cortex of conscious monkeys. Neuropsychopharmacology. 2005;30:1861-9.

44. Léna I, Chessel A, Le Pen G, Krebs M-O, Garcia R. Alterations in prefrontal glutamatergic and noradrenergic systems following MK-801 administration in rats prenatally exposed to methylazoxymethanol at gestational day 17. Psychopharmacology. 2007;192:373-83.

45. Roenker NL, Gudelsky GA, Ahlbrand R, Horn PS, Richtand NM. Evidence for involvement of nitric oxide and GABAB receptors in
MK-801-stimulated release of glutamate in rat prefrontal cortex. Neuropharmacology. 2012;63:575-81.

46. López-Gil X, Artigas F, Adell A. Role of different monoamine receptors controlling MK-801-induced release of serotonin and glutamate in the medial prefrontal cortex: relevance for antipsychotic action. Int J Neuropsychopharmacol. 2009;12:487-99.

47. Amitai N, Kuczenski R, Behrens MM, Markou A. Repeated phencyclidine administration alters glutamate release and decreases GABA markers in the prefrontal cortex of rats. Neuropharmacology. 2012;62:1422-31.

48. Olney JW, Labruyere J, Price MT. Pathological changes induced in cerebrocortical neurons by phencyclidine and related drugs. Science. 1989:244:1360-2.

49. Kim JH, Lee JO, Lee SK, Moon JW, You GY, Kim SJ, et al. The glutamate agonist homocysteine sulfinic acid stimulates glucose uptake through the calcium-dependent AMPK-p38 MAPK-protein kinase C $\zeta$ pathway in skeletal muscle cells. J Biol Chem. 2011:286:7567-76.

50. Marinangeli C, Didier S, Ahmed T, Caillerez R, Domise M, Laloux C, et al. AMP-activated protein kinase is essential for the maintenance of energy levels during synaptic activation. iscience. 2018;9:1-13.

51. Sheikh-Bahaei N, Sajjadi SA, Manavaki R, McLean M, O'Brien JT, Gillard JH. Positron emission tomography-guided magnetic resonance spectroscopy in Alzheimer disease. Ann Neurol. 2018;83:771-8.

52. Pfund Z, Chugani DC, Juhász C, Muzik O, Chugani HT, Wilds IB, et al. Evidence for coupling between glucose metabolism and glutamate cycling using FDG PET and $1 \mathrm{H}$ magnetic resonance spectroscopy in patients with epilepsy. J Cereb Blood Flow Metab. 2000;20:871-8.

53. Balu DT. The NMDA receptor and schizophrenia: from pathophysiology to treatment. Adv Pharmacol. 2016;76:351-82.

54. Wang $\mathrm{H}-\mathrm{Y}$, MacDonald ML, Borgmann-Winter KE, Banerjee A, Sleiman P, Tom A, et al. mGluR5 hypofunction is integral to glutamatergic dysregulation in schizophrenia. Mol Psychiatry. 2020:25:750-60.

55. Kinney GG, Burno M, Campbell UC, Hernandez LM, Rodriguez D, Bristow $\mathrm{LJ}$, et al. Metabotropic glutamate subtype 5 receptors modulate locomotor activity and sensorimotor gating in rodents. J Pharmacol Exp Ther. 2003:306:116-23.

56. Brambilla CR, Veselinović T, Rajkumar R, Mauler J, Orth L, Ruch A, et al. mGluR5 receptor availability is associated with lower levels of negative symptoms and better cognition in male patients with chronic schizophrenia. Hum Brain Mapp. 2020;40:2762-81.

57. Mirbolooki MR, Upadhyay SK, Constantinescu CC, Pan M-L, Mukherjee J. Adrenergic pathway activation enhances brown adipose tissue metabolism: a [18F]FDG PET/CT study in mice. Nucl Med Biol. 2014:41:10-6.

58. Bilbao A, Falfán-Melgoza C, Leixner S, Becker R, Singaravelu SK, Sack M, et al. Longitudinal structural and functional brain network alterations in a mouse model of neuropathic pain. Neuroscience. 2018;387:104-15.

59. Lutkenhoff ES, van Erp TG, Thomas MA, Therman S, Manninen M, Huttunen MO, et al. Proton MRS in twin pairs discordant for schizophrenia. Mol Psychiatry. 2010;15:308-18.

60. Cline GW, Zhao X, Jakowski AB, Soeller WC, Treadway JL. Islet-selectivity of $\mathrm{G}$-protein coupled receptor ligands evaluated for PET imaging of pancreatic $\beta$-cell mass. Biochem Biophys Res Commun. 2011:412:413-8.

61. Patterson S, Irwin N, Guo-Parke H, Moffett RC, Scullion SM, Flatt PR, et al. Evaluation of the role of $\mathrm{N}$-methyl-D-aspartate (NMDA) receptors in insulin secreting beta-cells. Eur J Pharmacol. 2016;771:107-13.

\section{Publisher's Note}

Springer Nature remains neutral with regard to jurisdictional claims in published maps and institutional affiliations. 